Hernández Conesa, Juana Mª; Torralba Madrid, Mª José; Navarro Perán, Mª Ángeles (2013). Correspondencia entre la ideología político-educativa del franquismo y el contenido de las asignaturas obligatorias de moral profesional y religión de los estudios enfermeros. Revista de Investigación Educativa, 31 (1), 199-221.

http://dx.doi.org/10.6018/rie.31.1.157001

\title{
CORRESPONDENCIA ENTRE LA IDEOLOGÍA POLÍTICO-EDUCATIVA DEL FRANQUISMOY EL CONTENIDO DE LAS ASIGNATURAS OBLIGATORIAS DE MORAL PROFESIONALY RELIGIÓN DE LOS ESTUDIOS ENFERMEROS
}

\author{
Juana $M^{a}$ Hernández Conesa*, $M^{a}$ José Torralba Madrid* $M^{a}$ Ángeles Navarro Perán ${ }^{* *}$ \\ * Profesora Titular de Universidad. Universidad de Murcia \\ *** Doctoranda Facultad de Enfermería. Universidad de Murcia
}

\section{RESUMEN}

Con este estudio hemos establecido la correspondencia entre la ideología y la política-educativa franquista en los estudios enfermeros en España. La investigación pone de manifiesto, a través del análisis gadameriano de los Contenidos de las asignaturas de Moral Profesional y Religión, la determinante influencia de la Iglesia Católica en esta enseñanza. Asimismo, hemos construido un debate específico, hasta ahora inexplorado, acerca de los Contenidos y sus Destinatarios, llevándonos a concluir que, los estudios de Enfermería durante el Franquismo, se determinan como una enseñanza "sin un fin en sí misma". El cambio de denominación de estos estudios, de Enfermera en Ayudante Técnico Sanitario, relega otros objetivos educativos relacionados con el desarrollo de aptitudes de reflexión crítica y científica. Todo ello implica una redefinición social de esta enseñanza.

Palabras clave: Historia de la Educación; Historia de la Enfermería; Historia Contemporánea.

\footnotetext{
Correspondencia:

Juana Mª Hernández Conesa: Facultad de Enfermería. Campus de Espinardo. 30100. Universidad de Murcia. jhconesa@um.es
}

Investigación subvencionada por el Consejo General de Enfermería de España. 


\title{
RELATION BETWEENTHE POLITICO-EDUCATIONAL IDEOLOGY OF THE FRANCO REGIME AND CONTENTS OF COMPULSORY SUBJECTS SUCH AS PROFESSIONAL MORAL AND RELIGION IN NURSING STUDIES
}

\begin{abstract}
In this study we analyzed the relationship between ideology and educational policy in nursing studies during the Franco regime in Spain. Using Gadamer's analysis of the Contents of compulsory subjects such as Professional Morality and Religion, this study showed the crucial influence of the Catholic Church in teaching. Also, we initiated and developed a discussion, unexplored until then, on Contents and Recipients, which led us to conclude that nursing studies during the Franco regime were defined to be "aimless". A change in the terminology from Nurse to Registered Nurse set aside other educational objectives related to the development of scientific and critical thinking skills. This implies a social redefinition in teaching.

Keywords: History of Education; History of Nursing; Contemporary History: Franco.
\end{abstract}

\section{INTRODUCCIÓN}

\section{I.I. Enfoque de correspondencias entre la ideología franquista y las políticas edu- cativas enfermeras}

La correspondencia dentro de cualquier orientación ideológica o político-educativa y su carácter, naturaleza, finalidad, contenidos y destinatarios, se constituye en lo que podríamos denominar un "principio general", que la legislación y la investigación histórica ratifican como tal. De este modo, el análisis de este entramado, descubre las complejas relaciones entre los fenómenos: educativo, social e ideológico, procurándonos el basamento científico discursivo. Asimismo, y partiendo de esta consideración, como premisa previa, entendemos que los Contenidos de las materias de Moral Profesional y Religión, establecidos para la formación de enfermeras durante el Franquismo, constituyen un terreno especialmente fértil para el análisis de correspondencias ideológicas y político-educativas. En dichas categorías argumentales se basa esta investigación, en donde los fenómenos, a su vez, cuentan con un excelente armazón para el debate acerca de la ideología, finalidad, contenidos educativos, y destinatarios.

En cuanto a la ideología-mentalidad, existe unanimidad entre los investigadores a la hora de afirmar que la Iglesia de Roma ha sido la única institución que ha conservado la tradición de la Teología Española de los siglos XVI y XVII, siendo, asimismo, la encargada de la predicación y de la catequesis como modelo ideológico-educativo, que el Franquismo asume plenamente, para todo el entramado social.

La finalidad de los estudios de Enfermería, se determina dentro de las coordenadas seculares de vocación y caridad cristiana a las que durante la época a estudio, se suman: la técnica y la dependencia y sumisión intelectual al modelo hegemónico médico. Del mismo modo, los contenidos analizados en esta investigación, son la expresión de las funciones ancestrales de la enfermera, así como de las futuras acti- 
vidades y ocupaciones sociales que pretende el Franquismo para estos estudiantes. En los contenidos de las materias de Religión y Moral Profesional, podemos establecer una precisa correspondencia entre la ideología y la política educativa franquista, y que se establece, como reglada y obligatoria, para la formación de las enfermeras. Por otra parte, los Destinatarios - futuras enfermeras - han de redefinirse socialmente, en relación a otros estudiantes a los que no se destinaban materias como la Religión y la Moral Profesional dentro del Plan de Estudios y/o no se les somete a la relación sustantiva en la denominación de ayudantes.

Con todo, de entre las distintas y posibles finalidades u objetivos de la educación de las enfermeras, la predominante y la que determinó su configuración definitiva fue, sin duda, la denominación desvirtuada de: Ayudante Sanitaria frente a la secular de Cuidadora de personas desvalidas o enfermas. Del mismo modo, la formación en Moral Profesional y Religión, junto a la sumisión intelectual al modelo biomédico contribuyó a hacer de ella una enseñanza sin un sentido en sí misma.

En la creencia de que este tipo de estudios contribuyen a profundizar cualitativamente en la correspondencia entre ideología y política-educativa nos hemos planteado analizar, mediante un análisis gadameriano, el contenido de las asignaturas de Moral Profesional y Religión, durante el Franquismo y su repercusión en el paradigma educativo enfermero. De este modo, en esta investigación, se constata la correspondencia entre la ideología franquista y las políticas educativas destinadas a la formación de las enfermeras.

En cuanto a las fuentes documentales utilizadas en esta investigación, hemos de decir que son fuentes primarias y que no han sido objeto de estudio con anterioridad, por lo que no se ha podido establecer una discusión contrastada de nuestros resultados.

\section{I.2. Naturaleza del entramado socio educativo franquista}

A partir de 1936, al Papa Pío XI no le resultó difícil tomar una nueva táctica ideológica, anti-republicana, hecho que contó con el beneplácito del General Franco. Tras la II República los esfuerzos de ésta, no habían cristalizado, los niveles de escolarización eran bajos, el analfabetismo era muy elevado y se mantenía intacta la estructura escolar clasista. A partir de 1939 se concretan esfuerzos antilaicistas, defendiendo a ultranza los intereses que la Iglesia de Roma marcaba, lo que presuponía el mantenimiento de un sistema de "enseñanza neo-feudal". La Iglesia recobra sus privilegios. Aparece una nueva "Inquisición" que no iba a favorecer, en modo alguno, la investigación y el desarrollo independiente y armónico de la Educación, la Ciencia y la Cultura.

En este entramado social, el Estado ofrecía seguridad a la Iglesia y ésta como contrapartida le proporcionaba un sistema ideológico basado en la doctrina del "pecado original" que concordaba con la concepción fascista del gobierno que bebía en las fuentes de Donoso Cortés y Menéndez Pelayo, entre otros. En el campo educativo serían Luis Vives y San José de Calasanz los elegidos por la ideología Franquista (Chao Rego, 1976). No obstante, la formación enfermera sigue bajo los paradigmas de: profesión no universitaria, maternal-instintiva, amparada en las 
cualidades morales frente al conocimiento, así como en la obediencia y la subordinación (Junquera, 1933).

El Opus Dei ${ }^{1}$, a partir de 1949, adquiere un gran prestigio dentro de las filas del Régimen. Víctor García Hoz, Ángeles Galino, y José Fernández Huerta, entre otros, intentarán dar una visión pedagógica de signo religioso, a base de vivificar en los estudiantes la idea de lo sobrenatural y conjugarlo con una vida profesional basada en la responsabilidad y el espíritu de sacrificio.

Para la formación enfermera el Opus Dei planifica una educación absolutamente femenina bajo la dimensión de "mujer-consagrada". Si bien, el espíritu en todos los centros educativos, desde la Escuela hasta la Universidad, sigue la línea ideológica del "hogar cristiano". La entrada de Ruiz Giménez en el Ministerio de Educación en 1951 refuerza el liberalismo católico, con un lenguaje más realista y menos dogmático, así como una mentalidad que da más valor a la preparación técnica. Esto continúa incluso hasta 1953, adaptándose una política educativa a los cambios pedagógicos, para intentar dar solución a las deficiencias funcionales del sistema y responder con nuevos objetivos curriculares en los nuevos contextos y propósitos políticos (Maillo, 1989: 5-30). Es en este contexto donde se insertan los estudios de las Carreras Auxiliares de la Medicina, que se unificaran en España durante el Franquismo bajo la denominación de Ayudante Técnico Sanitario (Vicario Peraita, 1968).

En 1969 el Ministerio de Educación y Ciencia, presentaba un documento indicador básico acerca de una futura y completa reorganización del Sistema Educativo Español, conocido como el "Libro Blanco". Por primera vez se reconocían los problemas que arrastraba el Sistema Educativo, tales como: insuficiente dotación docente, fracaso escolar, falta de orientación profesional, falta de eficacia en los métodos didácticos, entre otros. Como vías de solución se apuntaban: la creación de una estructura educativa relacionada o ajustada a la estructura ocupacional, la consecución de una escolarización básica sólida y suficiente, el fomento de una enseñanza superior y una investigación que promovieran el desarrollo social y cultural y la aplicación del principio de educación permanente. Todo ello, insistiendo, en que la educación debía inspirarse en la concepción Cristiana y en los Principios del Movimiento Nacional (Cuadernos para el Dialogo, $\mathrm{n}^{\mathrm{o}}$ 66, 1969: 7). A partir del Libro Blanco y de su consecuencia, la Reforma Educativa de 1970, se pretende mejorar la calidad y el rendimiento del Sistema Educativo, y de este modo se inicia el tiempo de lo que se ha denominando "transición política".

Nuestro estudio se inserta en el seno de una formación no universitaria, y ajena a la Reforma Educativa de 1970, y se enmarca en el análisis histórico-educativo, acerca del elemento moral-religioso como agente pedagógico de orientación profesional.

\section{METODOLOGÍA}

Para desvelar la correspondencia entre la ideología franquista y las políticas educativas destinadas a las enfermeras, a través de los textos formativos objeto de estudio

1 Institución perteneciente a la Iglesia Católica. Fue fundada el 2 de octubre de 1928 por Jose María Escrivá de Balaguer, sacerdote español canonizado en 2002. El término latino «Opus Dei» significa «obra de Dios» en http: //es.wikipedia.org/wiki/Opus Dei, consultado el 2/7/ 2011. 
de esta investigación, y hacer de ella "conciencia histórica-educativa", el planteamiento metodológico que hemos seguido se basa en los diseños de la "hermenéutica de lo fáctico".

De este modo, hemos considerado la "Palabrea" como los fenómenos que sometemos a interpretación. Para ello, hemos relacionado concepto y palabra y por ende, explicado pensamiento y lenguaje para, asimismo, establecer las relaciones conceptuales como espacios significativos de explicación ideológica-educativa (Hernández Conesa, 2011:58). La hermenéutica gadameriana², nos permite explicar la correspondencia ideológica del sistema educativo enfermero durante el Franquismo, bajo el prisma de la comprensión y la interpretación.

\section{Proceso de búsqueda documental:}

Para obtener la documentación de este estudio se han consultado los fondos documentales de:

$\checkmark$ La Biblioteca Nacional de Madrid.

$\checkmark$ El Archivo Nacional de la Cruz Roja de Madrid.

$\checkmark$ La Biblioteca de la Universidad de Murcia.

$\checkmark$ Biblioteca Regional de la Comunidad Autónoma de Murcia.

$\checkmark$ Biblioteca Pública del Estado de Orihuela, Alicante.

$\checkmark$ Biblioteca del Ilustre Colegio Oficial de Diplomados en Enfermería de la Comunidad de Madrid.

$\checkmark$ Fundación Index de Granada.

$\checkmark$ Biblioteca Casa Siervas de María, Plaza Chamberí, Madrid.

$\checkmark$ Biblioteca Histórica de la Universidad Complutense de Madrid.

$\checkmark$ Biblioteca del Palacio Real de Madrid.

$\checkmark$ Archivo de la Fundación Jiménez Díaz.

$\checkmark$ Biblioteca Central de la Universidad de Alicante.

La búsqueda se ha realizado en el catálogo de éstos centros mediante la utilización de las palabras clave: Enfermería, Ética del Cuidado, Moral Profesional, y Religión. Acotando el periodo de la búsqueda a los años 1939-1975, obteniendo las fuentes primarias que justifican este estudio.

2 La hermenéutica Gadameriana se presenta dentro de un especial desarrollo ontológico e histórico, en el que busca destacar el acontecer de la verdad y el método necesario para llegar a ese acontecer. En su formación fue fuertemente influenciado por el pensamiento de Husserl y especialmente por su maestro Heidegger. En http://www.monografias.com/trabajos11/gadamer/gadamer.shtml4 Consultado el 4 de septiembre 2011. 


\section{RESULTADOSY DISCUSIÓN}

\section{I. Correspondencia entre ideología franquista y política educativa enfermera, a través de la interpretación gadameriana de los contenidos de los textos de Moral Profesional y Religión}

Hemos de destacar que "se dividen los autores de los textos para la profesión Enfermera de 1939 a 1956 como la etapa del conservadurismo y autores tradicionales; y de 1957 a 1975 como la profesionalización práctica y autores en desarrollo" (Domínguez Alcón, 1986: 50-150).

El análisis de los manuales orientados a la Formación Moral y Religiosa de la época, lo realizamos por un lado, con una agrupación en dos periodos que comprenden a los autores más eminentes en Moral Profesional y Religión, y un tercer apartado que nos revela la correspondencia ideológica y la política formativa enfermera durante el franquismo, a través de los manuales de Moral Profesional y Religión, en donde se advierte las claras orientaciones católicas de la época.

a) El periodo de 1939 a 1956 se descifra a través de los autores: Idelio Pérez, Felipe Sáenz de Cenzano, Box María Cospedal, Felipe S. Pumulier, Manuel Usandizaga, Lorenzo García Tornel, Alonso García Sierra.

De ellos, Manuel de Usandizaga (Usandizaga, 1964), Lorenzo García Tornel (García Tornel, 1952) y Alonso García Sierra (García Sierra, 1945) solo aportan en sus manuales exclusivamente formación técnica y biomédica.

El autor Idelio Pérez (1942), en su obra de Deontología Moral Sanitaria, pone al descubierto que, "salvo algún que otro capítulo insertado como apéndice a los libros que tratan de la formación teórica y práctica de los auxiliares del médico, apenas si existen obras que se ocupen, con la extensión y el método debidos, de las obligaciones religiosas y morales a que practicantes, matronas, enfermeras, enfermeros, visitadoras, entre otras, están sometidos en el ejercicio de sus respectivas carreras u oficios" (Idelio Pérez 1942), además lo justificamos con el contenido de su índice, que incluye contenidos en Moral Profesional y Religión que marcan el periodo, en el podemos resaltar temas como el secreto profesional y las bases para la elaboración de un Código Moral.

El contenido de moral profesional dentro del manual de Felipe Sáenz de Cenzano (1942), lo encontramos en el tomo I, en el apartado de preliminares, enfocado a la deontología, por un lado, con una serie de indicaciones que asigna a las "relaciones de los Auxiliares con el médico, farmacéutico y la sociedad". Y por otro lado nos muestra las "condiciones morales científicas que deben adornar al Auxiliar Médico [....] sentimiento del deber, paciencia, prudencia, amabilidad, sencillez y caridad"(Sáenz de Cenzano, 1942: 9-29).

Box María Cospedal (1947), en su obra pese a abarcar en su mayoría contenido técnico y biomédico, destina en el tomo I, capítulo segundo "misión, actividades y cualidades de los auxiliares del médico", describe cuales son "las actividades y deberes globalmente, ya que su conocimiento será instructivo, cualquiera que sea el puesto a que se aspire; cada uno se aplicará aquello que más útil le resulte, según su labor específica". Detalla la misión, actividades y deberes, cualidades físicas, cualidades morales, cualidades intelectuales del "auxiliar del médico" (Box María Cospedal, 1947:19-46). 
San Juan de Dios $y$ a San Camilo de Lelis Celestiales Patronos ante Dios de todas las asociaciones de enfermeros (practicantes) y de todos los enfermeros (practicantes) de ambos sexos existentes en el presente $y$ que en adelante existan en toda la tierra. Esto queremos y mandamos, decretando que las presentes Letras sean y permanezcan siempre firmes, válidas y eficaces, y que debe juzgarse $y$ definirse que ahora y para siempre se determina que surtan $y$ obtengan sus plenos e integros efectos para aquellos a quienes se refieren y en adelante se referirán; asimismo invalidamos y anulamos todo cuanto en adelante se intentare hacer contra estas determinaciones por cualquier autoridad, ya se haga a sabiendas, ya por ignorancia. No obstante cualquier cosa en contrario.

Dado en Roma, en San Pedro, bajo el anillo del Pescador, el día 28 del mes de Agosto del año 1930, noveno de nuestro Pontificado.-L. S.-E. Cardenal Pacelli, Secretario de Estado.

Ved, pues, practicantes $\mathbf{y}$ enfermeras que vais leyendo cuál es la voz de Roma y la voluntad del Papa: San Camilo y San Juan de Dios son los protectores, los abogados, los Patronos celestiales tecte Dios de todos vosotros. "Esto querestiales ante Dios de todosisos. mandas $y$ asilismos cuanto en adelante se intentare hacer contra estas hacera". Ellos os ban haga a sabiendas ya por ignorancia". Ellos os han precedido en el anor a los pobres enfernos, ellos velan desde el Cielo por vosotios, ellos os alcanzaión. Honradles, invocadles, imitadles.

INDICE 2

144
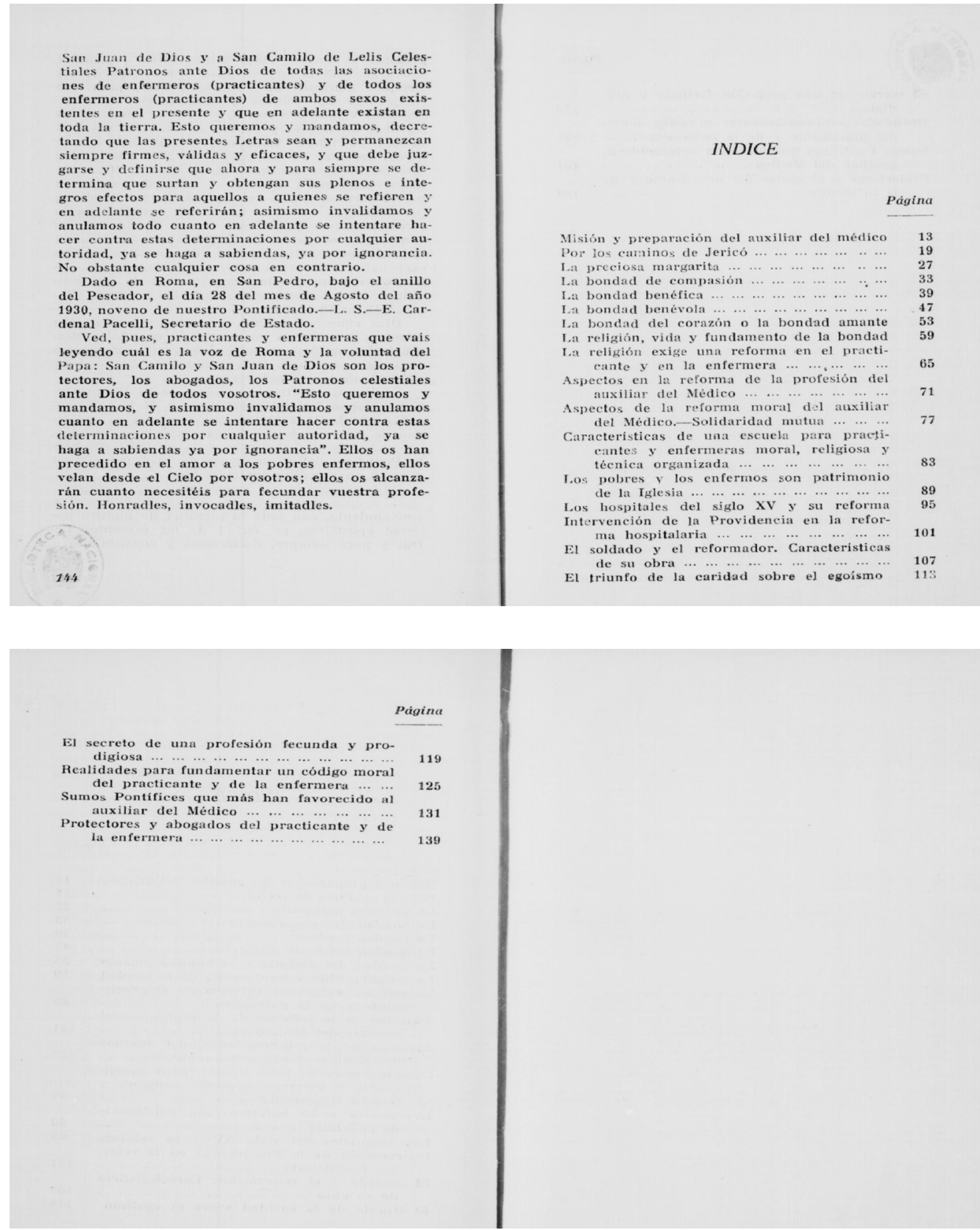

FIGURA 1

Fuente Primaria. Índice original de la obra Idelio Pérez. Biblioteca Nacional de Madrid. 
Por último, Felipe S. Pumulier (1949), en la introducción de su manual del practicante, expresa una serie de reflexiones respecto a las "consideraciones físicas y morales de los Auxiliares Sanitarios Practicantes para el desempeño de su misión, así como una serie de deberes respecto para con los enfermos, los Médicos y compañeros" (Pumilier, 1949:1-3).

b) Durante el periodo de 1956 hasta 1975, destacamos a dos grandes autores, que marcan el contenido de los valores morales y religiosos de los Ayudantes Técnicos Sanitarios, María Rosa Miranda (1956) y Juan Rey (1960). Asimismo, tomamos en consideración las aportaciones de otros autores como: Lázaro M. de Mendijur (1964), Eduardo Vicario Peraita (1968) con un asesoramiento legal respecto a la formación y profesionalización Enfermera (derechos, obligaciones, normativa educativa...) y Mำ Jesús Aranguren Iraizozya (1975).

María Rosa Miranda, enfermera y misionera, dirige exclusivamente su obra a la orientación en moral profesional, cumpliendo con los requisitos de adaptación al programa de Ayudante Técnico Sanitario. E.n la introducción de su obra nos revela: "mucho importa en este terreno la preparación técnica, la educación profesional, las diferentes prácticas que abarcan un tan amplio campo de conocimientos, pero esto es solo una parte. Debe ir unido al conocimiento moral, la formación de la conciencia profesional, la delicadeza del espíritu cristiano que caldea el corazón con el fuego de la caridad divina que inclina la voluntad a la práctica de las obras de misericordia". (Miranda, 1956: 5). Su obra refleja en diez temas todas las perspectivas de la orientación moral en la enfermera, qué se entiende por moral, la vocación, cualidades físicas, cualidades morales, deberes respecto al enfermo, deberes respecto a los familiares y allegados, deberes respecto a sus compañeros de profesión, deberes con la Institución a que pertenecen y deberes respecto a sí mismo.

Juan Rey, para algunos investigadores, el más representativo en este periodo formativo, dedica íntegramente su obra a la Formación Enfermera en moral profesional con tres manuales dedicados a los tres cursos obligatorios de Ayudante Técnico Sanitario, nos revela en el prólogo: "un tratadito que sirviera a los alumnos no solo para preparar las clases y los exámenes, sino también para tenerlo a mano en el ejercicio de la profesión y recordar las soluciones a los diversos casos según se vayan presentando" ( Rey, 1960: 5-10). El primer manual del primer curso de Ayudante Técnico Sanitario (ATS) con un total de diez temas y 178 páginas, coincide en la exposición con los mismos contenidos teóricos de la obra de María Rosa Miranda. En el segundo manual del segundo curso de ATS trata con otros diez temas el concepto de Ley, las propiedades de la Ley, elementos esenciales del acto humano, elementos modificados del acto humano, de la conciencia, el acto moral, los pecados de cooperación, de la eutanasia, de la eugenesia, de la obligación de advertir al enfermo cuando llega el peligro de muerte (Rey 1960). Y en el tercer libro adaptado para el tercer curso de ATS, hallamos trece temas que tratan las teorías modernas sobre la limitación de la natalidad, las operaciones prohibidas por la moral, los anovulatorios, el aborto directo, el aborto indirecto, los casos en teoría probablemente lícitos y seguros en la práctica, los procedimientos lícitos para regular los nacimientos, la fecundación artificial, el bautismo de urgencia, viático y unción de los enfermos, las clases de secreto, el secreto médico, y las causas 
excusantes del secreto médico (Rey, 1970). Algunos de los contenidos tratados en los dos últimos libros podemos encontrarles similitudes con lo que hoy en día conocemos como Ética, o con más precisión, al contenido actual de la Bioética.

El autor Lázaro M. de Mendijur contempla un " libro dirigido especialmente a enfermeras a quienes habla de su vocación, de sus deberes, responsabilidades, espíritu de sacrificio, comportamiento con el enfermo y con el médico, pero también se disponen en el mismo otros temas que no sólo interesan a las enfermeras, sino a los mismos enfermos y a todos los que sienten alguna inquietud sobre el problema de la enfermedad, como son Biología y dolor, cuerpo y alma en el enfermo, valoración de la enfermedad, derechos y deberes de los enfermos, el cristianismo ante la enfermedad [...]" (Mendijur, 1964:5).

M ${ }^{a}$ Jesús Aranguren Iraizozya enfoca la Formación Enfermera en Moral “a alguna actividad para la que tiene inclinación voluntaria (vocación) y que realiza con continuidad y dedicación (autodisciplina) [...]. Enfatiza una serie de "condiciones o dotes humanas con 4 rasgos principalmente: inteligencia, estabilidad, capacidad de trabajo y capacidad de entrega", además dedica un apartado completo a la formación humana de la Enfermera, la describe como "tarea difícil", recurre a los términos de "sacerdocio de la enfermera [...] y auténtica vocación cristiana de amor al prójimo [...]" (Aranguren, 1975: 21-34).

c) La relación directa y exclusiva de la Religión Católica en la Formación Enfermera es comprensible a través de los manuales de autores tan relevantes como: Aniceet Cool, (1962), P. Fischer (1960), Aldo Leoni (1962), y el Manual de las Hijas de la Carida .(1942).

Aniceet Cool publica un manual dedicado "a nuestras enfermeras, comadronas, visitadoras, asistentes sociales y, sobre todo a las jóvenes católicas que con la caridad de Cristo en sus almas se inclinan sobre las miserias humanas, en una obra de apostolado y de piedad" (Aniceet Cool, 1962, P. 7). Debido a la extensión e importancia de la obra proporcionamos el índice original del contenido, poniendo de manifiesto la clara orientación religiosa de la misma.

$\mathrm{El}$ autor P. Fischer en el prologo argumenta la misma "pero nos faltaba una deontología del apostolado religioso de los sanitarios. Y ésta es precisamente la laguna que viene a llenar sobradamente la traducción al español de la obra del padre Fischer, escrita en alemán: El personal clínico como auxiliar en la cura de almas" [...] "una deontología del apostolado religioso de los sanitarios, dirigido principal y directamente al Ayudante Técnico Sanitario [...]" (P. Fischer, 1960, P.6-7). En el índice pone de manifiesto abiertamente la relación formación Enfermera y Religión Católica.

El autor Aldo Leoni en su manual además del contenido general en Moral Profesional al igual que anteriores autores, en el capítulo I punto II pone de manifiesto la misión moral específica del Profesional Católico. Aportamos el índice de la obra con los contenidos de la misma. 

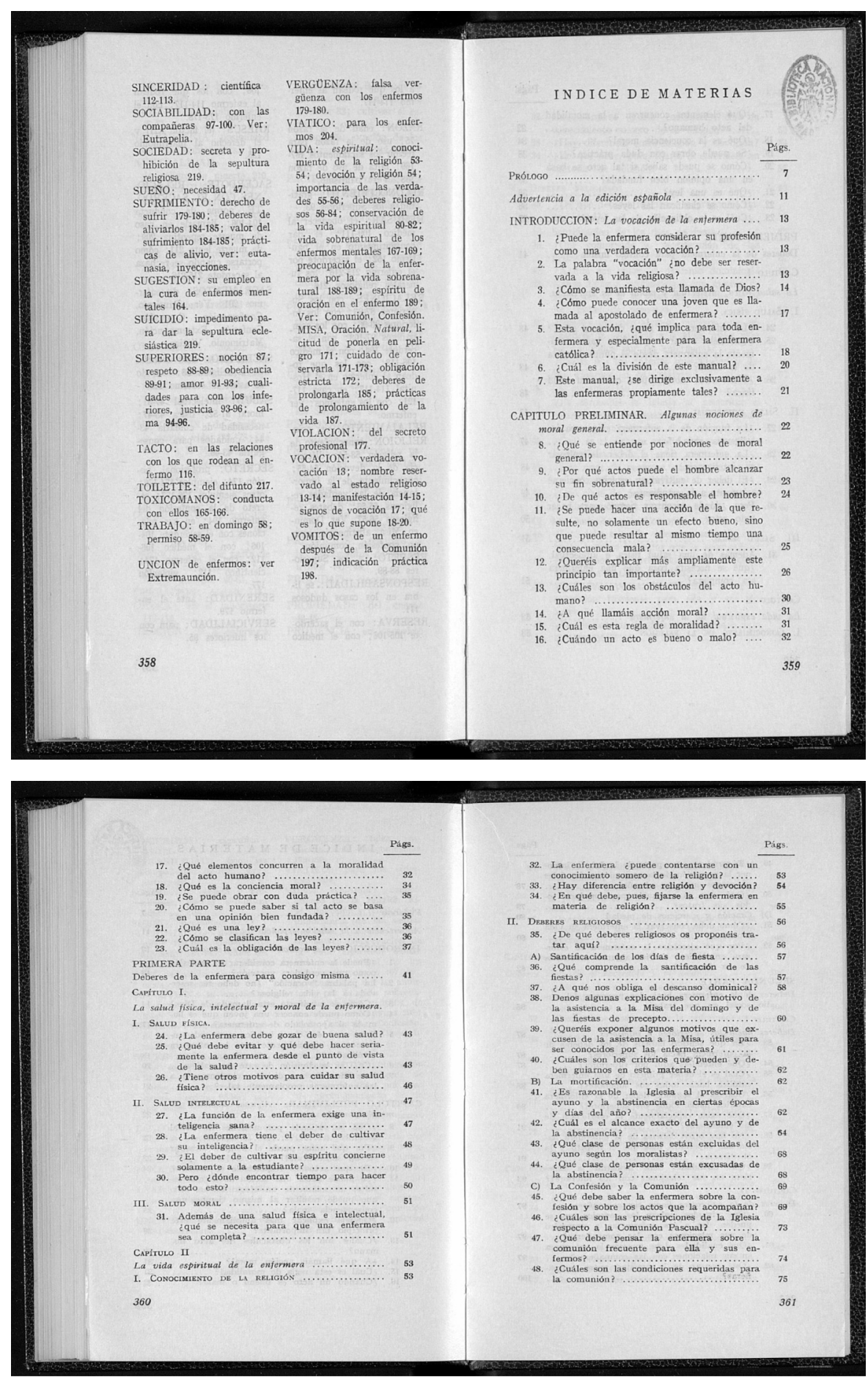

RIE, vol. 31-1 (2013) 

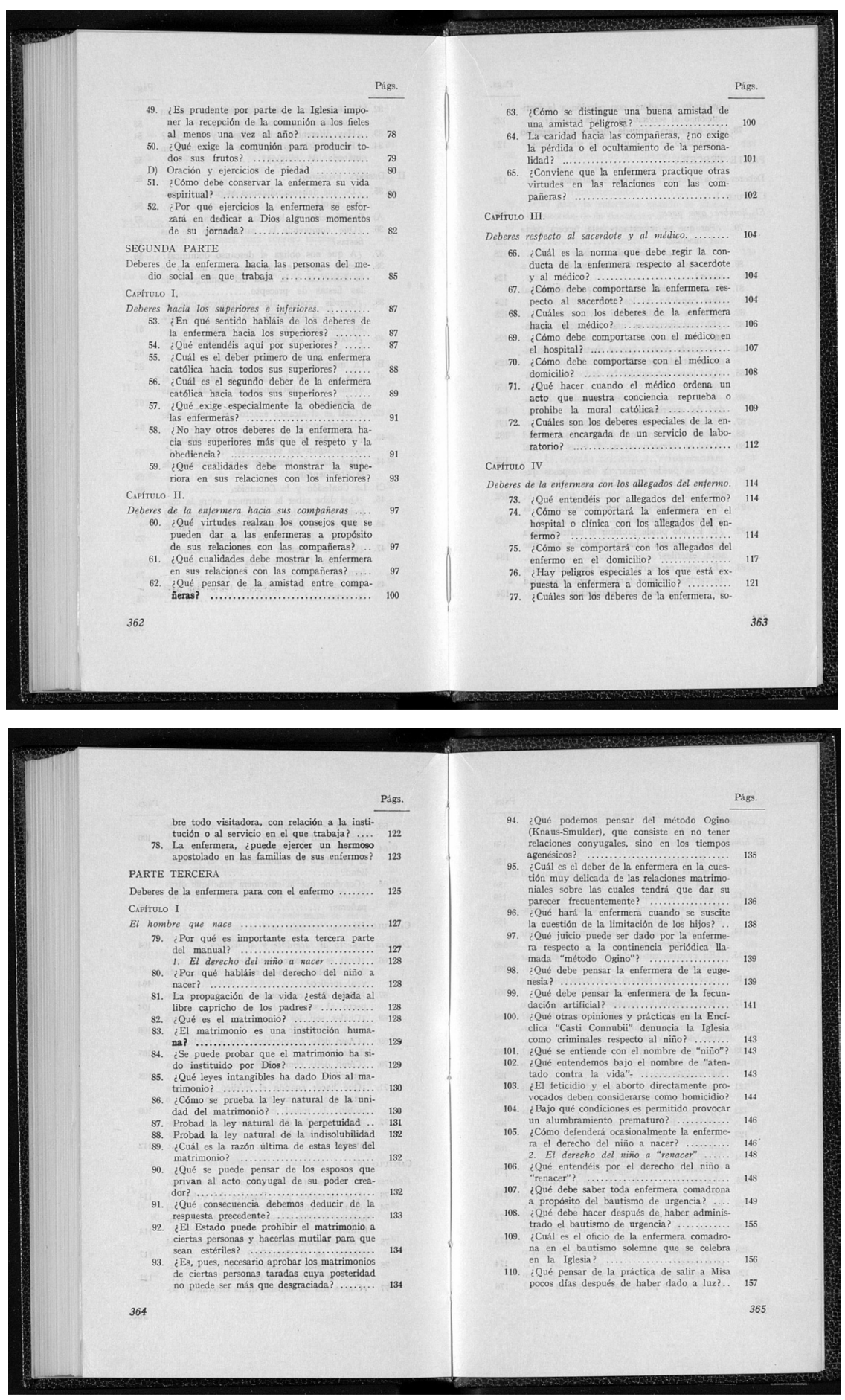

RIE, vol. 31-1 (2013) 

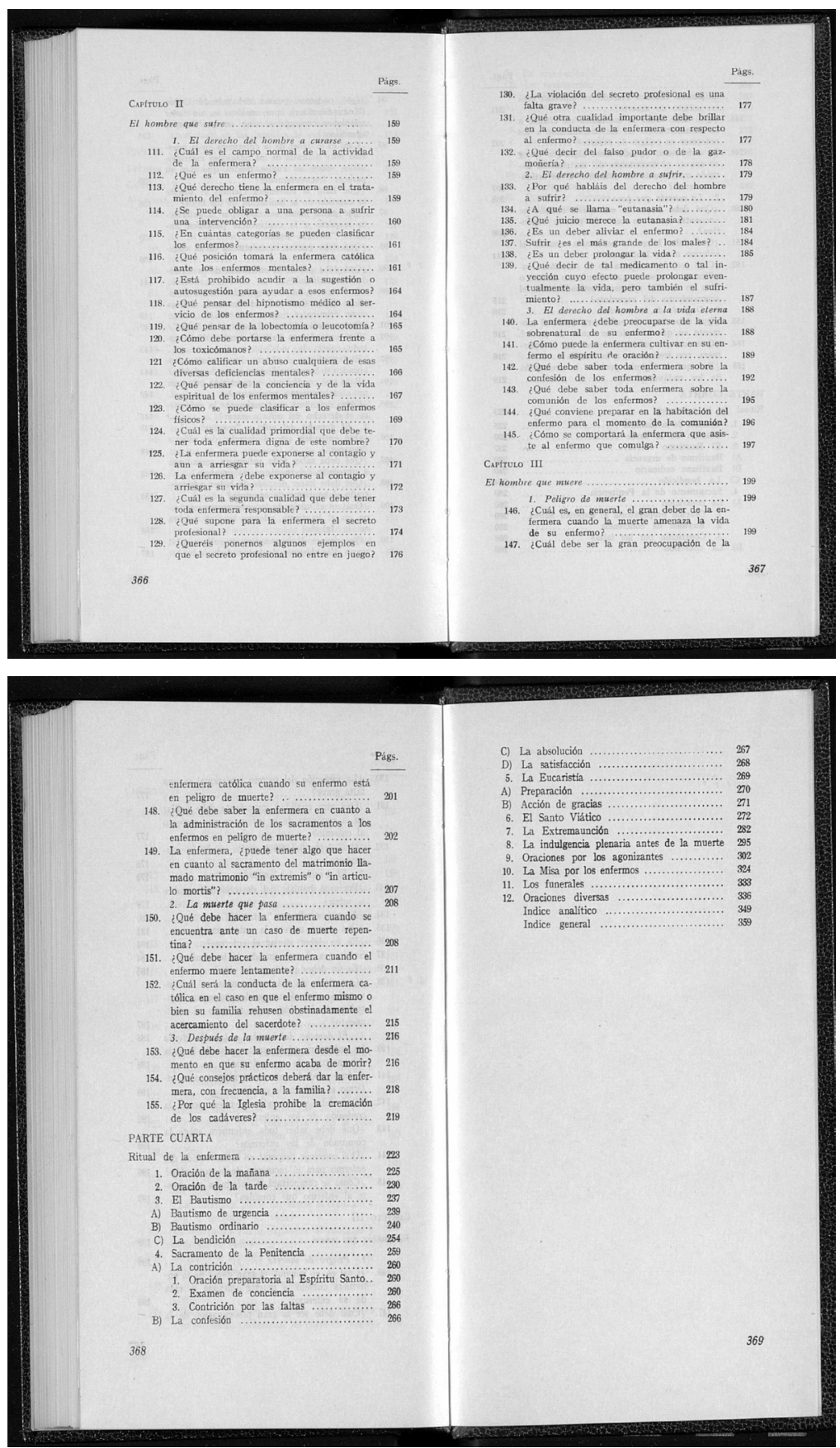

FIGURA 2

Fuente Primaria. Índice original obra de Aniceet Cool. Biblioteca Nacional de Madrid. 

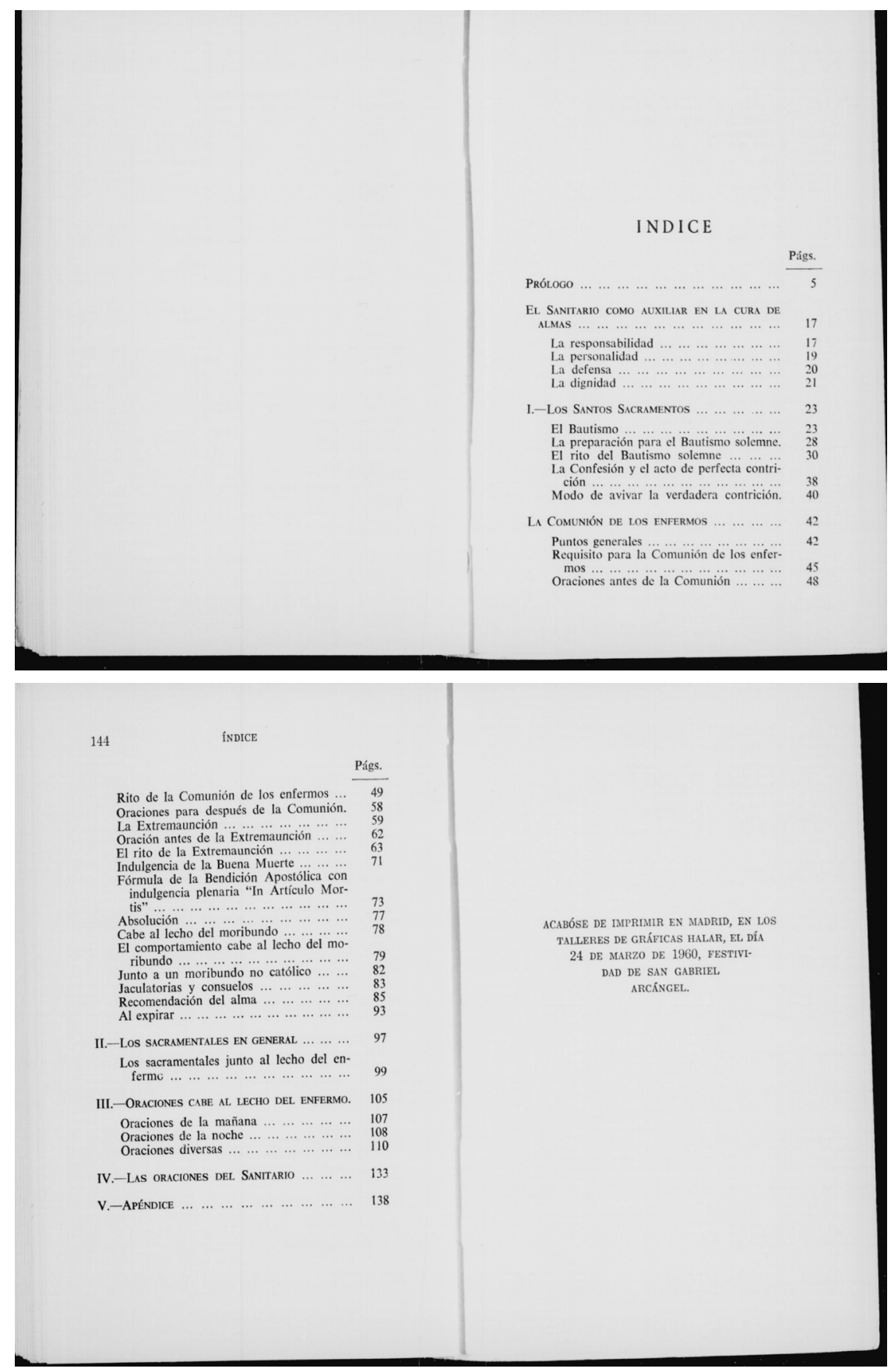

FIGURA 3

Fuente Primaria. Índice original obra de P. Fischer. Biblioteca Nacional de Madrid 

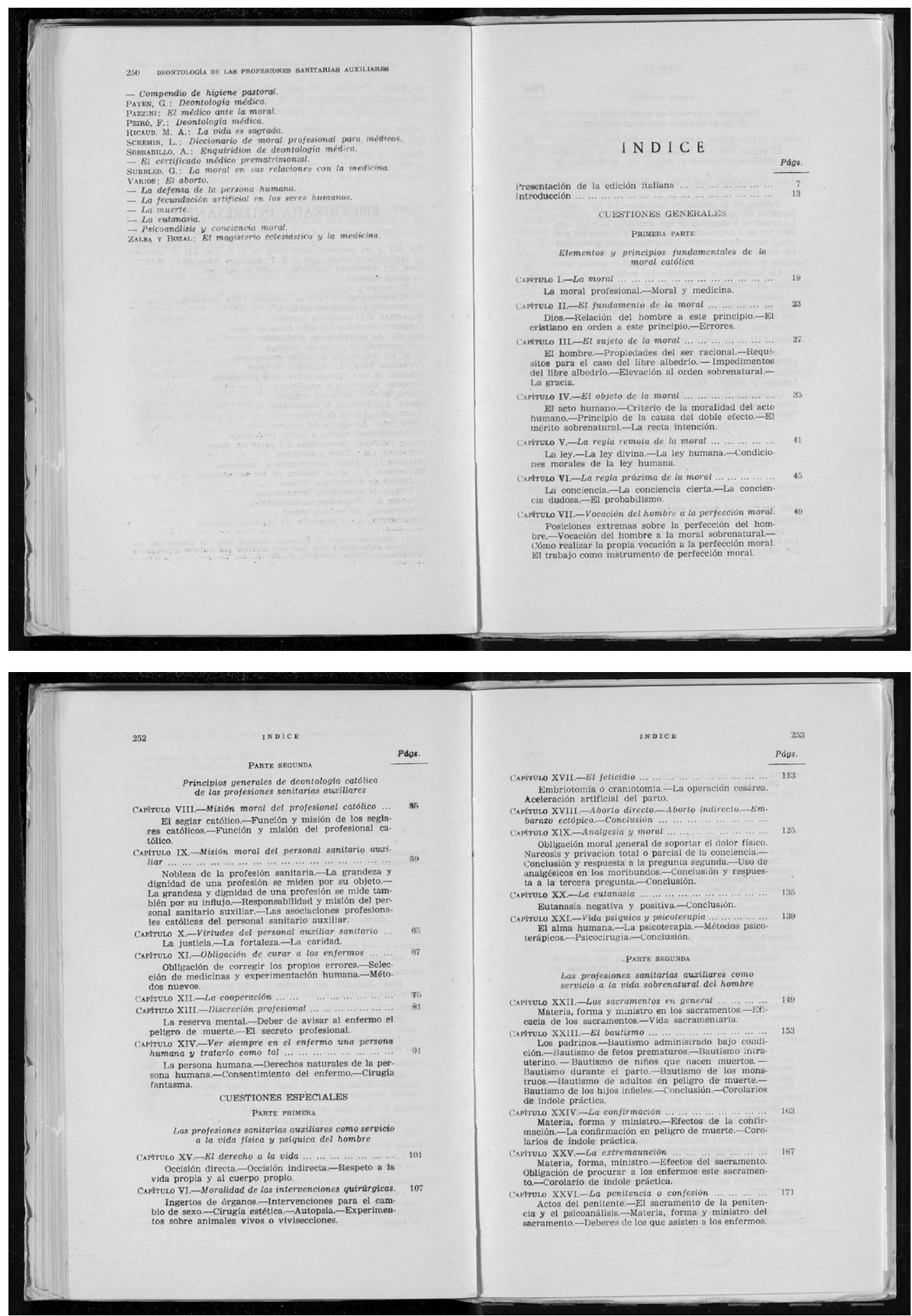


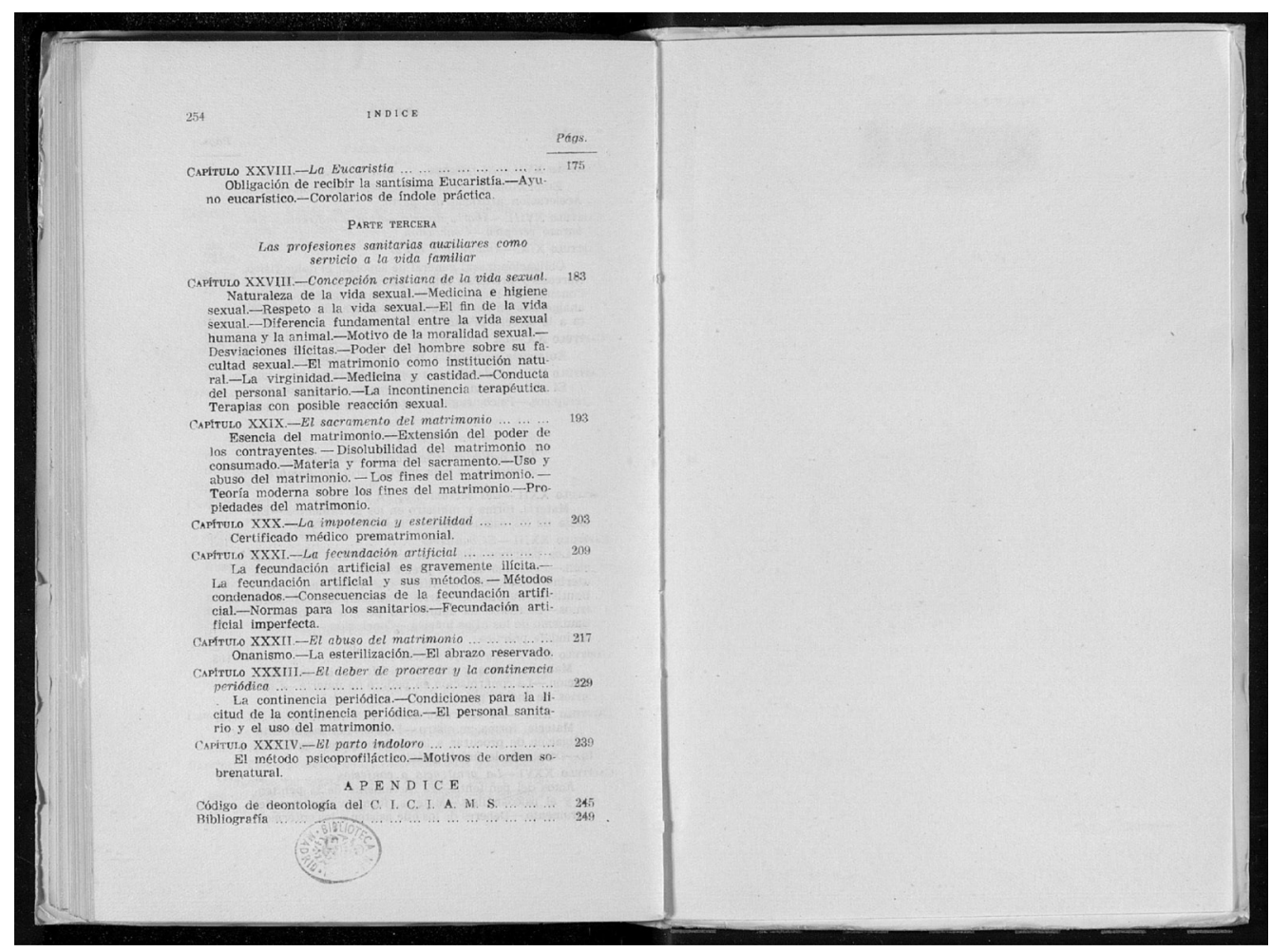

FIGURA 4

Fuente Primaria. Índice original de la obra de Aldo Leoni. Biblioteca Nacional de Madrid

El Manual de las Hijas de la Caridad, en la carta prólogo de Carlos L. Souvay declara "el Señor de la Caridad espera de la irradiación de vuestro celo en este ministerio de la salvación de las almas colocadas por Él mismo en vuestro camino, a fin de que vosotras las conduzcáis a Él" (Manual Hijas de la Caridad, 1942: 9). En el índice de materias podemos apreciar la orientación religioso-vocacional de esta orden religiosa dedicada al cuidado de los pobres y/o enfermos. 

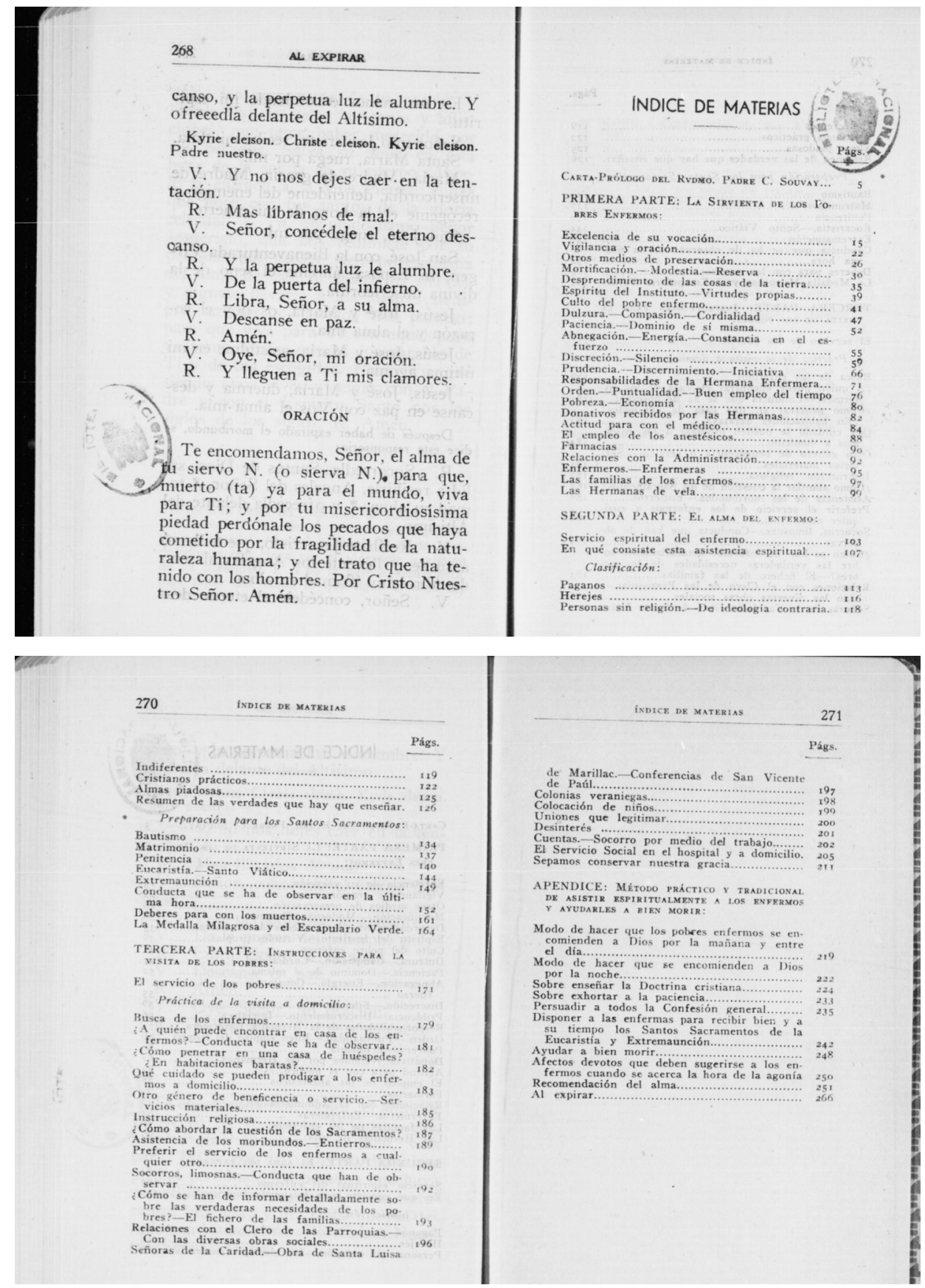

FIGURA 5

Fuente Primaria. Índice original del Manual de las Hijas de la Caridad. Biblioteca Nacional de Madrid. 
Asimismo, el autor José Álvarez Sierra y Manchón en colaboración con el Dr. Jorge Murga y Serret (1965), expone la implicación de las indicaciones Católicas en la asistencia a los enfermos en su capítulo II, dentro de un manual con amplios contenidos biomédicos y técnicos para la formación enfermera de la época, "pese a todos los detractores y textos sectarios, la influencia del Cristianismo en la asistencia de los enfermos ha sido positiva y a ella se debe casi todo su esplendor [...]" (Sierra y Manchón, 1965: 9).

Para finalizar este apartado, el autor Manuel Gutiérrez Alonso dedica su obra exclusivamente a dar una serie de normas y orientaciones de carácter religioso para la Enfermeras al servicio de la Seguridad Social, declara "además de las cualidades físicas, intelectuales y morales que exige tu profesión de Enfermera, exige también espíritu de apostolado discreto y prudente, respetuoso con la conciencia del enfermo, activo y lleno de caridad". (Gutiérrez Alonso, 1966: 3), explica el vínculo de la Enfermera y ciertos Sacramentos como el bautismo, la asistencia a moribundos, y una serie de virtudes y cualidades, entre ellas la caridad, seguida por la bondad, la abnegación, la vocación, sin olvidar que para ello se requiere salud, ciencia y conciencia.

\subsection{Enfoque de la enseñanza enfermera}

Con la recopilación de los Programas Formativos, que anexamos en la tabla I y II, aprobados para las Carreras Auxiliares de la Medicina y para los estudios de ATS,

TABLA 1

DESCRIPCIÓN DE LA NATURALEZA DE LOS ESTUDIOS ENFERMEROS

Asignaturas y Áreas de Conocimientos de los Programas de Estudio

Fuente: Gaceta de Madrid y Boletín Oficial del Estado (varios números).

Adaptado de Domínguez Alcón 1986

\begin{tabular}{|c|c|c|c|}
\hline Asignaturas/Áreas de conocimientos & 1939-1952 & Asignaturas/Áreas de conocimientos & 1939-1952 \\
\hline Anatomía & SÍ & Medicina Preventiva & SÍ \\
\hline Fisiología & SÍ & Matemáticas aplicadas & SÍ \\
\hline Patología (general, médica quirúrgica) & SÍ & Física & SÍ \\
\hline Medicina-cirugía de urgencia & SÍ & Química aplicada & SÍ \\
\hline Psiquiatría & SÍ & Sociología & SÍ \\
\hline Obstetricia & SÍ & Farmacología & SÍ \\
\hline Materno-Infantil & SÍ & Técnica y cuidado de enfermos & SÍ \\
\hline Higiene-Bacteriología & SÍ & Psicología & SÍ \\
\hline Enfermedades transmisibles & SÍ & Medicina social & SÍ \\
\hline Dermatología & SÍ & Educación física & SÍ \\
\hline Dietética. & SÍ & Historia de la profesión. & SÍ \\
\hline Moral Profesional & SÍ & Formación política. & SÍ \\
\hline Religión & SÍ & Hogar. & SÍ \\
\hline Biología-Histología. & SÍ & Enfermería fundamental & SÍ \\
\hline Microbiología-Parasitología. & SÍ & Ciencias de la conducta y psiquiatría. & SÍ \\
\hline Puericultura-Pediatría. & SÍ & Enfermería médico-quirúrgica. & SÍ \\
\hline Salud pública. & SÍ & Geriatría. & SÍ \\
\hline Terapéutica física. & SÍ & & \\
\hline
\end{tabular}


conjuntamente al contenido biomédico y técnico, precisamos la reveladora presencia de la materia de Moral Profesional y Religión, y destacamos que además se cursaba con carácter obligatorio.

TABLA 2

DESCRIPCIÓN DE LA NATURALEZA DE LOS ESTUDIOS ENFERMEROS

Asignaturas y áreas de conocimientos de los Programas de Estudio Universidad de Madrid (1952-1977). Biblioteca Nacional de Madrid

\begin{tabular}{|c|c|c|c|c|c|c|c|c|c|}
\hline \multirow[t]{2}{*}{ Asignaturas/Áreas de conocimientos. } & \multicolumn{3}{|c|}{1953} & \multicolumn{3}{|c|}{1955} & \multicolumn{3}{|c|}{1977} \\
\hline & $\begin{array}{c}\text { Primer } \\
\text { Curso } \\
\end{array}$ & $\begin{array}{c}\text { Segundo } \\
\text { Curso } \\
\end{array}$ & $\begin{array}{l}\text { Tercer } \\
\text { Curso }\end{array}$ & $\begin{array}{c}\text { Primer } \\
\text { Curso } \\
\end{array}$ & $\begin{array}{c}\text { Segundo } \\
\text { Curso }\end{array}$ & $\begin{array}{l}\text { Tercer } \\
\text { Curso }\end{array}$ & $\begin{array}{c}\text { Primer } \\
\text { Curso } \\
\end{array}$ & $\begin{array}{c}\text { Segundo } \\
\text { Curso }\end{array}$ & $\begin{array}{l}\text { Tercer } \\
\text { Curso }\end{array}$ \\
\hline Anatomía & \multicolumn{3}{|c|}{$X$} & \multicolumn{3}{|c|}{$\mathrm{X}$} & \multicolumn{3}{|c|}{$\mathrm{X}$} \\
\hline Fisiología & \multicolumn{3}{|c|}{$x$} & & & & & $x$ & \\
\hline Patología (general, médica quirúrgica) & \multicolumn{3}{|c|}{$x$} & \multicolumn{3}{|c|}{$\mathrm{XX}$} & & & \\
\hline Medicina-cirugía de urgencia. & & & & \multicolumn{3}{|c|}{$\mathrm{X}$} & & & \\
\hline Psiquiatría & \multicolumn{3}{|c|}{$X$} & & & & \multicolumn{3}{|c|}{$X$} \\
\hline Obstetricia. & \multicolumn{3}{|c|}{$x$} & & & & \multicolumn{3}{|c|}{$x$} \\
\hline Materno-Infantil & \multicolumn{3}{|c|}{$x$} & & & & & & \\
\hline Higiene-Bacteriología. & \multicolumn{3}{|c|}{$x$} & \multicolumn{3}{|c|}{$x$} & & & \\
\hline Enfermedades transmisibles. & \multicolumn{3}{|c|}{$x$} & \multicolumn{3}{|c|}{$x$} & & & \\
\hline \multicolumn{10}{|l|}{ Dermatología. } \\
\hline Dietética. & \multicolumn{3}{|c|}{$\mathrm{X}$} & \multicolumn{3}{|c|}{$\mathrm{X}$} & & & \\
\hline Moral Profesional & \multicolumn{3}{|c|}{$X X X$} & \multicolumn{3}{|c|}{$X X X$} & \multicolumn{3}{|c|}{$X X X$} \\
\hline Religión & & $X X X$ & & & $X X X$ & & & $X X X$ & \\
\hline Biología-Histología. & & $\mathrm{x}$ & & & & & & & \\
\hline Microbiología-Parasitología. & & & & & $x$ & & & & \\
\hline Puericultura-Pediatría. & & $x$ & & & & & & $x$ & \\
\hline Medicina Preventiva. & & $x$ & & & & & & & \\
\hline Matemáticas aplicadas. & & $x$ & & & & & & & \\
\hline Física. & & $x$ & & & & & & & \\
\hline Química aplicada. & & $x$ & & & & & & & \\
\hline Sociología. & & $x$ & & & & & & $X X$ & \\
\hline Farmacología. & & $x$ & & & & & & $X X$ & \\
\hline Técnica y cuidado de enfermos. & & $\mathrm{XX}$ & & & $\mathrm{X}$ & & & & \\
\hline Psicología & & $\mathrm{XX}$ & & & $\mathrm{XX}$ & & & & \\
\hline Medicina social. & & & & & $\mathrm{x}$ & & & & \\
\hline Educación física. & & $X X X$ & & & $X X X$ & & & & \\
\hline Historia de la profesión. & & $\mathrm{X}$ & & & $X$ & & & & \\
\hline Formación política. & & $X X X$ & & & $X X X$ & & & & \\
\hline Hogar. & & $X X X$ & & & & & & & \\
\hline Enfermería fundamental & & & & & & & & $\mathrm{X}$ & \\
\hline Ciencias de la conducta y psiquiatría. & & & & & & & & $X X X$ & \\
\hline Enfermería médico-quirúrgica. & & & & & & & & $\mathrm{XX}$ & \\
\hline Salud pública. & & & & & & & & $X X$ & \\
\hline Terapéutica física. & & & & & & & & $\mathrm{X}$ & \\
\hline Geriatría. & & & & & & & & $x$ & \\
\hline
\end{tabular}


La tabla I nos muestra las asignaturas que se cursaban con carácter obligatorio entre los años 1939 y 1953, poniendo de manifiesto la presencia de las asignaturas de Moral Profesional y Religión dentro del Plan de Estudios de Enfermeros de la época.

Del análisis de la tabla II, la cual representa al periodo entre 1952 y 1977, correspondiente a los estudios de Ayudante Técnico Sanitario, reflejamos marcando con una " $x$ ", el curso y el año en el cual se impartía la asignatura, y ponemos de manifiesto que las asignaturas de Moral Profesional y Religión, se daban durante todo el periodo, en los tres cursos formativos y con carácter obligatorio.

\section{CONCLUSIONES}

En este artículo se ha identificado la correspondencia entre la ideología y la política educativa franquista a través del carácter, naturaleza y finalidad asignados a los estudios de Enfermería. Este principio general, que la Normativa Jurídica y el Conocimiento Histórico nos confirman a través de las relaciones entre los fenómenos: educativo, social e ideológico, ha constituido el basamento de nuestra investigación. Asimismo, con el análisis gadameriano de los contenidos de las materias obligatorias, de Religión y Moral Profesional, en los estudios enfermeros, hemos construido un debate específico, hasta ahora inexplorado, acerca de los Contenidos y sus Destinatarios, llevándonos a concluir que, los estudios de Enfermería durante el Franquismo, se determinan como una enseñanza "sin un fin en sí misma".

Este debate sobre la correspondencia entre ideología y política educativa desvela, a su vez, la determinante influencia de la Iglesia Católica en los estudios enfermeros durante el Franquismo, en contraste con otros estudios, de las hoy denominadas Ciencias de la Salud. Todo ello, obliga a una redefinición social de estos estudios, que además, ven modificada su secular denominación por la unificada y desnaturalizada de: Ayudante Técnico Sanitario. Así, de entre las finalidades u objetivos, distintos y posibles, de estos estudios, emerge como conclusión preeminente la continuidad del paradigma cristiano-vocacional-caritativo y moralizante, que comporta, a su vez, la sumisión intelectual y la discriminación por razón de sexo. De esta manera, la autoría y la intención argumental del contenido de los textos formativos enfermeros, analizados en esta investigación, pone de manifiesto que la piedra angular de lo que podríamos denominar naturaleza del debate ideológico-educativo franquista enfermero se identifica, a la luz de los resultados obtenidos, con el establecimiento de una política-educativa ad hoc para las enfermeras, relegando otros objetivos educativos relacionados con el desarrollo de aptitudes de reflexión crítica y científica.

\section{BIBLIOGRAFÍA}

\section{I. Fuentes primarias}

Leoni, A. (1962). Deontología de las profesiones sanitarias. Madrid: Ed. Conculsa. Álvarez S. y Manchón, J. (1965). Historia de la profesión (enfermera-practicante-matrona) $2^{\underline{o}}$ curso. Madrid: Ed. Graficas Onofre Alonso. 
Aranguren Iraizoz, M.J.; et al (1975). Formación de la enfermera. Perspectivas de una formación. Pamplona: Universidad de Navarra.

Aznar Embrín, S. (1941). La misión social de la enfermera.

Bonel, M. (1940). Episodio de una Enfermera. Zaragoza: Ed. El Noticibro.

Box, A. (1947). Manual teórico practico para practicantes y enfermeras (2 tomos) 2ª edición. P. 19-46. Madrid: Ed. Reus centro de enseñanza y publicación S.A.

Conferencia del Vizconde de Eza. El alma femenina española (1940). Madrid.

Cool, A. (1962). Manual de la enfermera católica. Madrid: La milagrosa.

Decreto del Boletín Oficial del Ministerio de Educación Nacional de 8 de septiembre de 1955. Programa Oficial de Ayudante Técnico Sanitario (Unificación de carreras de practicantes, matronas y enfermeras) $1^{\circ}, 2^{\underline{o}}$ y $3^{\underline{o}}$ curso. Común a todas las Facultades de Medicina. Madrid, 1959.

Escuela de Ayudantes Técnicos Sanitarios "San Francisco de Asís". 1973. Codigo de Deontología de las Enfermeras. Madrid.

Escuela de Ayudantes Técnicos Sanitarios de Nuestra Señora de la Esperanza. Valencia, Imp. S. Almerich, 1959.

Esteban Romero, A. (1953). Pio XII enaltece la misión de las enfermeras. Revista Firmes, año $1, \mathrm{n}^{\mathrm{o}} 3$.

Fischer, P. (1960). El auxiliar sanitario en la cura de almas. Madrid: Studium.

García Sierra, A. (1945). Las carreras auxiliares médicas 5a ed. Madrid: Edit.

García Tornel, L. (1952). Manual del practicante y de la enfermera $5^{\underline{a}}$ edición. 2 Tomos. 589 págs. Barcelona: Bosch Casa Editorial.

Gutiérrez Alonso, M. (1966). Normas y orientaciones de carácter religioso para las enfermeras al servicio de la Seguridad Social. Madrid.

Huellín Martaza, R. (1942). La enfermera en el hogar y en la clínica. Manuales Prácticos Molinos. Buenos Aires, Argentina: Molino.

Mendijur, L. (1964). Enfermeras, enfermeros y moral. Madrid: Ed. Studium.

Manual de las hijas de la caridad (1942). Madrid. Ed. La milagrosa.

Miranda, M.R. (1956). Orientación de moral profesional. Madrid: Publicaciones Murga.

Murga y Serret, J. (1963). La enfermera española. 10ª edición.

Pérez, I. (1942). Deontología moral sanitaria del auxiliar del médico. Bilbao-Madrid: Ed. Imprimatur.

Programa de estudios para Damas Auxiliares Voluntarias Cruz Roja Española.

Programa de la Escuela de Enfermeras (ATS) dirigida por las R.R. Hospitalarias del Sagrado Corazón de Jesús. Madrid, octubre de 1959.

Pumilier, F.S. (1949). Manual del practicante. TOMO I. Madrid: Librería editorial científico medica española.

Reglamento de Régimen Interno Escuela de ATS Sevilla. Sevilla, 1968.

Reglamento del cuerpo de Damas Auxiliares Voluntarias Cruz Roja Española. Madrid. 1962.

Reglamento del cuerpo de Damas Auxiliares Voluntarias Cruz Roja Española. Madrid. 1969.

Reglamento del cuerpo de Damas Auxiliares Voluntarias Cruz Roja Española. Madrid. 1971.

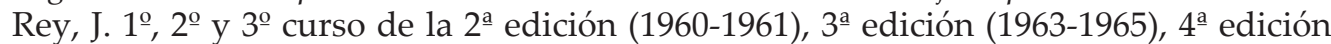

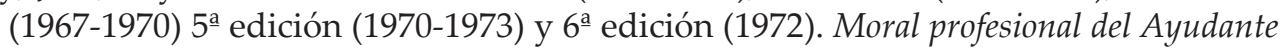
Técnico Sanitario, Santander, Editorial Sal Terrae. 
Rico Avelló C. (1962). Escuela de Ayudantes Técnicos Sanitarios Femeninos. Madrid: Gráficas González.

Sáenz de Cenzano, F. (1942). Manual del practicante. 3ํa edición. Zaragoza: Tip. Octavio y Félez.

Universidad de Barcelona. 1971. Estudios de Ayudantes Técnicos Sanitarios. Barcelona.

Universidad de Madrid. 1962. Ayudantes Técnicos Sanitarios. (Unificación de carreras de practicantes, matronas y enfermeras). Curso $1^{\circ}$. Madrid. Ed. Departamento de publicaciones de la Facultad de Medicina de Madrid.

Universidad de Madrid. 1962. Ayudantes Técnicos Sanitarios. (Unificación de carreras de practicantes, matronas y enfermeras). Curso $3^{\circ}$. Madrid. Ed. Departamento de publicaciones de la Facultad de Medicina de Madrid.

Universidad de Madrid. 1965. Ayudantes Técnicos Sanitarios. (Unificación de carreras de practicantes, matronas y enfermeras). Curso $1^{\underline{o}}, 2^{\underline{a}}$ edición. Madrid. Ed. Departamento de publicaciones de la Facultad de Medicina de Madrid.

Universidad de Madrid. 1966. Ayudantes Técnicos Sanitarios. (Unificación de carreras de practicantes, matronas y enfermeras), Curso 3ํㅜ $2^{a}$ edición. Madrid, Ed. Departamento de publicaciones de la Facultad de Medicina de Madrid.

Universidad de Madrid. 1966. Técnicos Sanitarios. (Unificación de carreras de practicantes, matronas y enfermeras). Curso $2^{\underline{o}}, 2^{\underline{0}}$ edición. Madrid. Ed. Departamento de publicaciones de la Facultad de Medicina de Madrid.

Universidad de Madrid. 1969. Ayudantes Técnicos Sanitarios. (Unificación de carreras de practicantes, matronas y enfermeras), Curso $1^{\underline{o}}$, $3^{\underline{a}}$ edición. Madrid. Ed. Departamento de publicaciones de la Facultad de Medicina de Madrid.

Universidad de Madrid. 1969. Ayudantes Técnicos Sanitarios. (Unificación de carreras de practicantes, matronas y enfermeras). Curso $3^{\underline{o}}, 3^{\underline{a}}$ edición. Madrid. Ed. Departamento de publicaciones de la Facultad de Medicina de Madrid.

Universidad de Madrid. 1970. Ayudantes Técnicos Sanitarios. (Unificación de carreras de practicantes, matronas y enfermeras), Curso $2^{\underline{o}} 4^{\underline{a}}$ edición. Madrid. Ed. Departamento de publicaciones de la Facultad de Medicina de Madrid.

Universidad de Madrid. 1970. Ayudantes Técnicos Sanitarios. (Unificación de carreras de practicantes, matronas y enfermeras). Curso $2^{\stackrel{o}{ }}$, $3^{\underline{a}}$ edición. Madrid. Ed. Departamento de publicaciones de la Facultad de Medicina de Madrid.

Universidad de Madrid. 1971. Ayudantes Técnicos Sanitarios (Unificación de carreras de practicantes, matronas y enfermeras). Curso 3무 $4^{\underline{a}}$ edición. Madrid. Ed. Departamento de publicaciones de la Facultad de Medicina de Madrid.

Usandizaga, M. (1964). Manual de la enfermera y del practicante. $8^{\underline{a}}$ edición. Madrid: Ed. Mayfe. Usandizaga, M. (1970). Manual de la enfermera y del practicante. 9a edición. Madrid: Ed. Mayfe. Vicario Peraita, E. (1968). Legislación de Ayudantes Técnicos Sanitarios, apéndice 1965, 66 y 67. Burgos: Talleres Gráficos Diario de Burgos.

\subsection{Fuentes Secundarias}

“En torno al Libro Blanco", en Cuadernos para el Dialogo, no 66, 1969.

Álvarez Nebreda, C. (2008). Catálogo bibliográfico de publicaciones enfermeras (1541-1978). Madrid: Colegio Oficial de Enfermería de Madrid. 
Álvarez Nebreda, C. (2010). Catálogo de publicaciones periódicas enfermeras (1864-1977). Madrid: Colegio Oficial de Enfermería de Madrid.

Bedmar Moreno, M., Montero García, I. (2010). Visión histórico-educativa en la España del franquismo. Influencias y repercusiones a través de los testimonios de vida de nuestros mayores. 2010. Revista de Investigación Educativa. 28 (1), 141-156.

Cantero González, M.L., Hernández Conesa, J.M., Beinet Montesinos, J.V. (2010). Formación e Identidad Enfermera en el Franquismo. Murcia: Colección Arte y Ciencia de la Sanación. Historia de la Educación. Diego Marín-Editor.

Castilla del Pino Cordón, F.; Gimferrer, P.; Giner, S.; González Ruiz, J.M.; Gubern, R.; Ivars, J.F.; Mones, J.; Monleón, J.; París, C.; Tamares, R.; M. Tuñón de Lara, M.; Vázquez Montalbán, M. (1977). La cultura bajo el Franquismo. Barcelona: Ed. Anagrama.

Chao Rego, J. (1976). La iglesia en el Franquismo. Madrid: Felmar.

Domínguez Alcón, C. (1986). Los cuidados y la profesión enfermera en España. Madrid: Ed. Pirámide.

Donahue, P. (1996). Historia de la enfermería. Barcelona: Doyma.

Equipo reseña. 1977. La cultura española durante el franquismo. Bilbao. Ediciones Mensajero.

Ferrandes Torres, M. Interpretación política de la Historia de España. Adaptado al programa oficial. Ed. Nuevas gráficas S.A.

Guillamón Álvarez, F.J. (1990). Metodología de la Historia, en Aspectos Metodológicos de la Investigación Científica. Murcia: Universidad de Murcia.

Hernández Conesa, J.M. (1996). La construcción de la enfermería como disciplina científica: una aproximación desde su historia y sus fundamentos teóricos. Tesis Doctoral. Murcia: Universidad de Murcia.

Hernández Conesa, J.M. (2011). Interpretación doctrinal comparativa entre el "Manuale dell Infermere Oosia Istruzione sul di Assistere i Malati" de Ernesto Rusca y "Notas sobre Enfermería. Qué es y Qué no es" de Florence Nightingale. Tesis Doctoral. Madrid: Universidad Complutense de Madrid.

Hernández, F. (Coord.). (1996). Historia de la enfermería en España. Desde la antigüedad hasta nuestros días. Madrid: Síntesis.

Jaques, G. (1971). El franquismo: Historia y balance 1939-1969. Edición Ruedo ibérico.

Junquera, M.T. (1933). Conferencia dictada en la Escuela de Enfermera del Hospital Central de la Cruz Roja Española en Madrid. 6 de Abril de 1933. Bajo el título: "Lo que puede y debe ser la Enfermera".

Maillo, A. (1989). Historia crítica de la Inspección Escolar en España. Madrid: Unión de Inspectores Técnicos de Educación.

Mayordomo, A. (Coord.); López Martín, R.; Martí Ferrándiz, J.J.; Bascuñana Cortes, J.; Aguiló Díaz, C. (1999). Estudios sobre la política educativa durante el franquismo. Valencia: Universidad de Valencia.

Morodo, R. (1985). Los orígenes ideológicos del Franquismo: Acción española. Madrid: Alianza editorial.

Pulido Mendoza, R., Hernández Conesa, J.M., Beneit Montesinos, J.V. (2011). La formación Enfermera de la Cruz Roja Española. Murcia: Colección Arte y Ciencia de la Sanación. Historia de la Educación. Diego Marín editor. 
Rebollo Catalán, M.Á.; Vega Caro, L.; García Pérez, R.. 2011 El profesorado en la aplicación de planes de igualdad: conflictos y discursos en el cambio educativo. Revista de Investigación Educativa, 29 (2), 311-323.

Revel, J.; Chartier, R. (1978). "Annales", en Le Goff, Jaques (ed.), La novelle histoire. París. De la Cierva, R. (1975). Historia del Franquismo. Orígenes y configuración (1939-1945). Barcelona: Planeta.

Sellán Soto, Ma .C. (2010). La profesión va por dentro. Elementos para una historia de la Enfermería Española contemporánea. $2^{a}$ Edición. Madrid: FUDEN.

Fecha de recepción: 31 de enero de 2012.

Fecha de revisión: 3 de febrero de 2012.

Fecha de aceptación: 2 de septiembre de 2012. 
